\title{
Perencanaan Sistem Penampung Air Hujan Sebagai Salah Satu Alternatif Sumber Air Bersih di Rusunawa Penjaringan Sari Surabaya
}

\author{
Fairuz Nadia dan Mas Agus Mardyanto \\ Jurusan Teknik Lingkungan, Fakultas Teknik Sipil dan Perencanaan, Institut Teknologi Sepuluh Nopember (ITS) \\ Jl. Arief Rahman Hakim, Surabaya 60111 Indonesia \\ e-mail: fnadia27@gmail.com
}

\begin{abstract}
Abstrak-Di Surabaya, ada banyak Rusunawa (apartemen sewa untuk masyarakat berpenghasilan rendah hingga menengah). Air bersih untuk penggunaan kebutuhan seharihari di Rusunawa diperoleh dari PDAM Surabaya. Biaya untuk konsumsi air yang dibayarkan oleh penyewa dianggap terlalu mahal karena penyewa sebagian besar memiliki pendapatan rendah atau menengah. Oleh karena itu, sumber lain untuk air bersih yang murah dan mudah perlu dipertimbangkan. Pemanenan air hujan (PAH) adalah salah satu alternatif yang dapat dipertimbangkan karena Surabaya merupakan daerah dengan curah hujan yang cukup tinggi. Tugas akhir ini akan membahas potensi air hujan sebagai sumber air bersih alternatif di Rusunawa. Air hujan dikumpulkan dari atap rusunawa tersebut. Kualitas air hujan dianalisis di laboratorium. Jumlah air hujan dihitung berdasarkan curah hujan rata-rata berdasarkan data selama sepuluh tahun. Air hujan yang dikumpulkan mengalir ke reservoir tanah yang ada serta yang baru sebelum didistribusikan kepada penyewa. Air hujan yang dikumpulkan secara umum memenuhi standar kualitas yang tercantum dalam Keputusan Menteri Kesehatan Nomor 42 Tahun 2010. Namun, kualitas air hujan agak sedikit asam; oleh karena itu, perlu dicampur dengan air PDAM. Air hujan dari atap setiap blok Rusunawa dikumpulkan di reservoir yang ada. Berdasarkan jumlah air hujan yang ditampung, total biaya untuk perencanaan ini sekitar Rp 558.930.070. Adapun prosentase penghematan terhadap pemakaian air PDAM selama 1 bulan untuk masing-masing blok $A=17,18 \%$; blok $B$ $=16,84 \%$; blok $\mathrm{C}=16,51 \%$; blok $\mathrm{DA}=19,10 \%$; blok $\mathrm{DB}=$ $17,02 \%$; blok $\mathrm{EA}=16,50 \% ;$ blok $\mathrm{EB}=17,56 \%$; blok $\mathrm{FA}=$ $19,69 \%$ dan blok $\mathrm{FB}=17,56 \%$.
\end{abstract}

Kata Kunci-air bersih, air hujan, kualitas, kuantitas, PAH.

\section{PENDAHULUAN}

$\mathrm{A}^{\mathrm{i}}$ ir adalah unsur yang tidak dapat dipisahkan dari kehidupan manusia. Bahkan dapat dipastikan tanpa pengembangan sumber daya air secara konsisten peradaban manusia tidak akan mencapai tingkat yang dinikmati sampai saat ini. Oleh karena itu, pengembangan dan pengolahan sumber daya air merupakan dasar peradaban manusia [1].

Konservasi sumber daya air dalam arti penghematan dan penggunaan kembali (reuse) menjadi hal yang sangat penting pada saat ini. Hal ini disebabkan oleh beberapa masalah yang berkaitan dengan ketersediaan air bersih seperti penurunan muka air tanah, kekeringan maupun dampak dari perubahan iklim. Pengelolaan sumber daya air yang berkelanjutan didasarkan pada prinsip bahwa sumber daya air seharusnya digunakan sesuai dengan kuantitas air yang dibutuhkan [2].
Air bersih di Rusunawa Penjaringan Sari dipasok dari PDAM Kota Surabaya dan masyarakat di Rusunawa Penjaringan Sari mengeluarkan biaya yang terbilang cukup mahal dibandingkan dengan biaya sewa satu unit di rusunawa tersebut. Hal ini sangat disayangkan karena masyarakat membayar cukup mahal, seperti dijelaskan dalam UU RI Nomor 20 Tahun 2011 tentang Rumah Susun tertera pada bab 2 pasal 3, bahwa penyelenggaraan rumah susun bertujuan untuk menjamin terpenuhinya kebutuhan rumah susun yang layak dan terjangkau [3]. Maka dari itu, pada studi perencanaan ini akan dipelajari dan direncanakan tentang usaha pemanfaatan air hujan sebagai salah satu alternatif sumber air bersih serta sebagai usaha penghematan penggunaan air bersih dan penghematan biaya pengeluaran masyarakat di kawasan Rusunawa Penjaringan Sari Surabaya.

\section{METODE PERENCANAAN}

Perencanaan ini meliputi aspek teknis dan aspek finansial. Aspek teknis dalam perencanaan ini meliputi perencanaan bak penampung air hujan dan perencanaan sistem penyaluran air hujan menuju bak penampung. Sementara aspek finansial meliputi perhitungan Bill of Quantity (BOQ) dan Rancangan Anggaran Biaya (RAB) serta perhitungan prosentase penghematan biaya pemakaian air bersih.

\section{A. Pengumpulan Data Primer dan Sekunder}

Data yang digunakan dalam perencanaan ini merupakan data primer yang didapatkan melalui survey dan uji laboratorium serta data sekunder yang diperoleh dari instansi terkait. Adapun data primer dan data sekunder yang dibutuhkan antara lain:

1) Data Primer

a) Kondisi lahan dan area di Rusunawa Penjaringan Sari yang memungkinkan dijadikan area penangkapan dan penampung air hujan

b) Data sistem penyediaan air bersih eksisting di bangunan Rusunawa Penjaringan Sari

c) Kebutuhan air bersih per orang per hari didapatkan dari penyebaran kuisioner.

d)Data kualitas air hujan dan air PDAM didapatkan dengan melakukan uji laboratorium di Laboratorium Pemulihan Air Teknik Lingkungan FTSP ITS. Sampel air yang akan digunakan sebanyak 3 buah, yaitu sampel air hujan, sampel air PDAM yang berasal dari rusunawa, serta sampel campuran air hujan dengan air PDAM. Parameter 
yang akan diuji yaitu $\mathrm{pH}$, TDS dan kesadahan.

2) Data Sekunder

a) Jumlah penghuni Rusunawa Penjaringan Sari

b)Denah dan luas bangunan Rusunawa Penjaringan Sari

c) Peta lokasi dan site plan rusunawa

d)Data curah hujan selama 10 tahun terakhir dari BMG

\section{B. Pengolahan Data}

Pengolahan data mencakup aspek teknis maupun aspek finansial.

1)Aspek Teknis

Tahapan perencanaan dalam aspek teknis adalah sebagai berikut:

a) Perhitungan Kebutuhan Air Bersih

Perhitungan kebutuhan air bersih berdasarkan data jumlah penghuni Rusunawa Penjaringan Sari dan kebutuhan air bersih per orang per hari yang datanya didapatkan dari kuisioner. Jumlah koresponden kuisioner didapatkan dari rumus Richard L. Schaffer seperti pada persamaan (1) dan (2).

$$
\begin{aligned}
& D=\frac{B^{2}}{4} \\
& n=\frac{N(p(1 \quad p)}{\left(\begin{array}{lll}
N & 1) D+p(1 \quad p
\end{array}\right)}
\end{aligned}
$$

Dimana:

$\mathrm{n}=$ jumlah sampel

$\mathrm{N}=$ jumlah populasi

$\mathrm{p}=$ proporsi pengambilan sampel

$\mathrm{B}=$ error tolerance

b)Penentuan Kualitas Air Hujan

Kualitas air hujan didapatkan dari uji laboratorium yang akan digunakan untuk menentukan penggunaan air hujan sebagai pengganti air bersih dalam kehidupan sehari-hari.

c) Perhitungan Curah Hujan yang Dapat Ditampung

Berdasarkan data curah hujan yang didapatkan dari stasiun BMG, serta luas atap bangunan maka dapat dilakukan perhitungan terhadap curah hujan yang dapat ditampung untuk kawasan Rusunawa Penjaringan Sari. Perhitungan curah hujan yang dapat ditampung dapat dilihat pada persamaan (3).

$S=A \quad M \quad F$

Dimana:

$\mathrm{S}$ = supply air hujan yang dapat diterima $\left(\mathrm{m}^{3}\right)$

A $=$ luas area penangkapan air hujan $\left(\mathrm{m}^{2}\right)$

$\mathrm{M}=$ curah hujan rata-rata $(\mathrm{mm} / \mathrm{bulan})$

$\mathrm{F}=$ koefisien pengaliran atau run-off [4]

d)Perhitungan Kapasitas Tangki Penampung Air Hujan

Perhitungan kapasitas tangki penampung air hujan dapat dilakukan setelah menghitung debit curah hujan yang ditampung. Adapun rumus yang digunakan dapat dilihat pada persamaan (4).

$$
V=S \quad B
$$

Dimana:

$\mathrm{V}=$ volume bak penampung $\left(\mathrm{m}^{3}\right)$

$\mathrm{S}=$ supply air hujan yang dapat diterima $\left(\mathrm{m}^{3}\right)$

$\mathrm{B}=$ total kebutuhan air dalam satu bulan $\left(\mathrm{m}^{3}\right)$

e) Perancangan Talang Datar dan Talang Tegak

Perancangan talang datar dan talang tegak pada perencanaan ini meliputi perhitungan dimensi talang serta sistem perpipaan dari talang itu sendiri menuju ke ground reservoir. Perhitungan dimensi talang datar dan talang tegak membutuhkan data luas atap perencanaan, curah hujan pada PUH 1 tahun dan intensitas air hujan. Perhitungan dimensi talang datar dan talang tegak mengacu pada SNI 03-7065-2005 Tentang Tata Cara Perencanaan Sistem Plambing.

\begin{tabular}{|c|c|c|c|c|c|c|c|c|c|}
\hline \multirow{2}{*}{\multicolumn{2}{|c|}{ Diameter pipa }} & \multirow{3}{*}{$\begin{array}{l}\text { Pipa tegak air } \\
\text { hujan }\end{array}$} & \multirow{2}{*}{\multicolumn{3}{|c|}{$\frac{\text { Pipa datar pembuangan air hujan }}{\text { Kemiringan }(\%)}$}} & \multirow{2}{*}{\multicolumn{4}{|c|}{$\frac{\text { Talang atap datar terbuka }}{\text { Kemiringan }(\%)}$}} \\
\hline & & & & & & & & & \\
\hline inch & $\mathrm{mm}$ & & 1 & 2 & 4 & 0,5 & 1 & 2 & 4 \\
\hline 2 & 50 & 63 & & & & & & & \\
\hline $21 / 2$ & 65 & 120 & & & & & & & \\
\hline 3 & 80 & 200 & 75 & 105 & 150 & 15 & 20 & 30 & 40 \\
\hline 4 & 100 & 425 & 170 & 245 & 345 & 30 & 45 & 65 & 90 \\
\hline 5 & 125 & 800 & 310 & 435 & 620 & 55 & 80 & 115 & 160 \\
\hline 6 & 150 & 1290 & 490 & 700 & 990 & 85 & 125 & 175 & 250 \\
\hline 8 & 200 & 2690 & 1065 & 1510 & 2135 & 180 & 260 & 365 & 520 \\
\hline 10 & 250 & & 1920 & 2710 & 3845 & 330 & 330 & 665 & 945 \\
\hline 12 & 300 & & 3090 & 4365 & 6185 & & & & \\
\hline 15 & 375 & & 5525 & 7800 & 11055 & & & & \\
\hline
\end{tabular}

Tabel 1

Berdasarkan curah hujan $100 \mathrm{~mm} / \mathrm{jam}$

Bila curah hujan lebih besar, nilai luas pada tabel tersebut di atas harus disesuaikan dengan cara mengalikan nilai luas atap wilayah perencanaan dengan 10 lalu dibagi kelebihan curah hujan dalam mm/jam kemudian ditambahkan dengan nilai luas atap wilaya perencanaan. Maka berdasarkan Tabel 1 tersebut maka akan didapatkan diameter untuk talang datar dan talang tegak.

f) Perancangan Sistem Penyaluran Air Hujan

Sistem penyaluran air hujan yang akan dirancang meliputi sistem perpipaan dari area tangkapan air hujan menuju tangki penampung air hujan yaitu ground reservoir serta dari ground reservoir menuju roof tank eksisting.

2)Aspek Finansial

Tahapan perencanaan dalam aspek finansial adalah sebagai berikut:

a) Perhitungan BOQ dan RAB

Berdasarkan perancangan, kemudian disusun kebutuhan jumlah dan macam material yang digunakan dalam sistem penampungan air hujan ini serta disusun rancangan anggaran biaya yang dibutuhkan. Penyusunan BOQ dan RAB mengacu pada HSPK Kota Surabaya yang berlaku dan Pt-S-04-2000-C tentang Petunjuk Teknis Spesifikasi Bak Penampung Air Hujan untuk Air Bersih dari Ferrosemen.

b)Perhitungan Prosentase Penghematan Biaya Pemakaian Air Bersih

Perhitungan prosentase penghematan biaya pemakaian air bersih didasarkan pada kebutuhan air bersih per bulan, jumlah air hujan yang dapat ditampung, dan harga air PDAM yang dikeluarkan oleh masyarakat Rusunawa Penjaringan Sari.

\section{HASIL DAN PEMBAHASAN}

\section{A. Analisis Hasil Survei}

Survei pada perencanaan mencakup penggunaan air bersih pada tiap blok rusunawa serta ketersediaan masyrakat terhadap penggunaan PAH (Penampungan Air Hujan). 
Kuisioner ini ditujukan untuk semua gedung mulai dari gedung di blok A hingga gedung di blok F. Kuisioner dilakukan dengan melakukan wawancara terhadap kepala keluarga atau perwakilan.

Kuisioner mengenai penggunaan air bersih selama sebulan memberikan hasil bahwa pada blok A, B, dan C tidak terdapat meteran air sehingga untuk data penggunaan air bersih pada blok A-C akan menggunakan ketentuan SNI 037065-2005. Sementara pada blok D-F terdapat meteran air di tiap unitnya sehingga dapat diperoleh data mengenai penggunaan air bersih selama sebulan. Penentuan penggunaan air bersih pada blok D-F dengan cara menjumlahkan kebutuhan air per KK kemudian dicari rataratanya. Tabel 2 menunjukkan rata-rata dari penggunaan air bersih yang ada di blok D-F.

Tabel 2.

Penggunaan Air Bersih Blok D-F

\begin{tabular}{cc}
\hline \hline BLOK & $\begin{array}{c}\text { Rata-Rata Kebutuhan } \\
\text { Air }\left(\mathbf{m}^{\mathbf{3}} / \text { bulan }\right)\end{array}$ \\
\hline DA & 19,58 \\
DB & 19,58 \\
EA & 20,00 \\
EB & 19,17 \\
FA & 17,69 \\
FB & 19,17 \\
\hline \hline
\end{tabular}

Data kebutuhan air bersih untuk blok A-C sebesar 100 liter/orang/hari [4]. Sementara data kebutuhan air bersih pada Tabel 2 digunakan untuk menghitung kebutuhan air bersih pada blok D-F. Dari kedua data tersebut dapat dilakukan perhitungan kebutuhan air untuk blok A-F yang disajikan pada Tabel 3 .

Tabel 3.

Kebutuhan Air di Rusunawa Penjaringan Sari Blok A-F

\begin{tabular}{|c|c|c|c|c|c}
\hline \multicolumn{6}{c}{ Kebutuhan Air di Rusunawa Penjaringan Sari Blok A-F } \\
\hline BLOK & $\begin{array}{c}\text { Jumlah } \\
\text { KK }\end{array}$ & $\begin{array}{c}\text { Jumlah } \\
\text { Orang } \\
\text { Per KK }\end{array}$ & $\begin{array}{c}\text { Jumlah } \\
\text { Penghuni } \\
\text { (jiwa) }\end{array}$ & $\begin{array}{c}\text { Kebutuhan air } \\
\text { per orang } \\
\left(\mathrm{m}^{3} / \text { orang.hari }\right)\end{array}$ & $\begin{array}{c}\text { Total } \\
\text { Kebutuhan } \\
\left.\text { Air ( } \mathrm{m}^{3} / \text { hari }\right)\end{array}$ \\
\hline A & 73 & 4 & 292 & 0,10 & 29,20 \\
\hline B & 74 & 4 & 296 & 0,10 & 29,60 \\
\hline C & 75 & 4 & 300 & 0,10 & 30,00 \\
\hline DA & 48 & 4 & 192 & 0,15 & 28,92 \\
\hline DB & 48 & 4 & 192 & 0,16 & 31,33 \\
\hline EA & 48 & 4 & 192 & 0,17 & 32,00 \\
\hline EB & 48 & 4 & 192 & 0,16 & 30,67 \\
\hline FA & 48 & 4 & 192 & 0,15 & 28,31 \\
\hline FB & 48 & 4 & 192 & 0,16 & 30,67 \\
\hline
\end{tabular}

Kuisioner mengenai ketersediaan masyarakat terhadap penggunaan PAH memberikan kesimpulan bahwa masyrakat bersedia untuk menggunakan PAH sebagai cadangan air bersih dan sebagai salah satu upaya penghematan biaya pengeluaran untuk air bersih. Berdasarkan hasil kuisioner didapatkan pula kesimpulan bahwa masyarakat lebih memilih hanya menggunakan air hujan sebagai sumber air pada PAH.

Rusunawa Penjaringan Sari Surabaya menggunakan sistem sewa per bulan, tidak diijinkan untuk membeli unit di rusunawa tersebut. Perencanaan ini mengasumsikan terdapat empat jiwa tiap unit yang terdiri dari satu bapak, satu ibu, dan dua orang anak.

\section{B. Analisis Pengolahan Data}

1)Kualitas Air Hujan dan Kualitas Air PDAM
Data kualitas air hujan dan air PDAM didapatkan dari data primer dengan melakukan sampling di wilayah Rusunawa Penjaringan Sari Surabaya. Pengambilan sampling air hujan dilakukan sekali saat terjadi hujan, dengan catatan lokasi pengambilan sampling dilakukan di tempat terbuka yang tidak terhalang atap ataupun ranting pohon sehingga air hujan langsung jatuh ke dalam wadah sampling. Sementara untuk sampling air PDAM dilakukan bersamaan saat sampling air hujan. Pengujian sampling air hujan dan air PDAM dilakukan di Laboratorium Pemulihan Air Jurusan Teknik Lingkungan FTSP ITS. Tabel 4 menunjukkan kualitas air hujan dan air PDAM.

Tabel 4.

Kualitas Air Hujan dan Air PDAM

\begin{tabular}{lccc}
\hline \multicolumn{1}{c}{ Sampel } & $\begin{array}{c}\text { Kesadahan } \\
(\mathbf{m g} / \mathbf{l})\end{array}$ & $\begin{array}{c}\text { Parameter } \\
\text { pH }\end{array}$ & TDS (mg/l) \\
\hline Air Hujan & 21,43 & 5,84 & 344,38 \\
Air Hujan (80\%)+ & 35,71 & 7,57 & 296,34 \\
Air PDAM (20\%) & & & \\
Air Hujan (50\%)+ & 78,57 & 7,79 & 255,54 \\
Air PDAM (50\%) & 150 & 7,98 & 104,17 \\
Air PDAM & $\mathbf{5 0 0}$ & $\mathbf{6 , 5 - 8 , 5}$ & $\mathbf{5 0 0}$ \\
BAKU MUTU [5] &
\end{tabular}

Berdasarkan hasil uji laboratorium didapatkan bahwa kualitas air hujan pada parameter $\mathrm{pH}$ belum memenuhi baku mutu, dan berdasarkan hasil kuisioner, masyarakat menginginkan sumber air pada PAH hanya berasal dari air hujan saja. Namun melihat dari hasil uji laboratorium, diambil alternatif sumber air pada PAH menggunakan campuran dari air hujan dan air PDAM. Hal ini dilakukan karena semua parameter yang diuji memenuhi baku mutu, sehingga tidak diperlukan lagi pretreatment yang rumit, hanya berupa filter sederhana. Alternatif ini nantinya akan disosialisasikan kepada masyrakat agar tidak terjadi kesalahpahaman.

2)Curah Hujan yang Dapat Ditampung

Data curah hujan berasal dari Stasiun Hujan Wonorejo. Stasiun Hujan Wonorejo dipilih sebagai sumber pengambilan data hujan karena jarak antara stasiun hujan dengan lokasi perencanaan cukup dekat yaitu $3,35 \mathrm{~km}$ serta wilayah cangkupan perencanaan tidak terlalu luas sehingga hanya menggunakan satu buah stasiun hujan. Tabel 5 menunjukkan data curah hujan harian maksimum selama 10 tahun pada Stasiun Hujan Wonorejo.

Tabel 5.

Curah Hujan Maksimum Stasiun Wonorejo Surabaya

\begin{tabular}{|l|c|c|c|}
\hline Tahun & $\begin{array}{c}\text { Curah HHM } \\
(\mathrm{mm} / \mathrm{hari})\end{array}$ & Bulan & Keterangan \\
\hline 2006 & 441 & Februari & \\
\hline 2007 & 366 & Desember & \\
\hline 2008 & 384 & Desember & \\
\hline 2009 & 363 & Februari & \\
\hline 2010 & 550 & Februari & \\
\hline 2011 & 345 & Maret & \\
\hline 2012 & 575 & Januari & $\begin{array}{c}\text { curah hujan maksimum } \\
\text { tahun ini }\end{array}$ \\
\hline 2013 & 451 & Januari & \\
\hline 2014 & 436 & Maret & \\
\hline 2015 & 529 & Desember & \\
\hline
\end{tabular}

Tabel 5 menunjukkan bahwa pada bulan Januari tahun 2012 terjadi hujan dengan curah tertinggi, sehingga data curah hujan pada bulan Januari tahun 2012 akan dijadikan 
pedoman dalam menghitung supply curah hujan pada perencanaan ini. Tabel 6 dan Tabel 7 menunjukkan hasil perhitungan kuantitas hujan.

Tabel 6.

Kuantitas Air Hujan Blok A-C

\begin{tabular}{|c|c|c|c|}
\hline Hari & $\begin{array}{c}\text { Curah Hujan } \\
(\mathbf{m m})\end{array}$ & Luas Atap $\left(\mathbf{m}^{2}\right)$ & $\begin{array}{c}\text { Volume supply } \\
\left(\mathbf{m}^{\mathbf{3}}\right)\end{array}$ \\
\hline 1 & 75,0 & 665 & 44,90 \\
\hline 2 & 80,0 & 665 & 47,90 \\
\hline 3 & 0,0 & 665 & 0,00 \\
\hline 4 & 0,0 & 665 & 0,00 \\
\hline 5 & 50,0 & 665 & 29,94 \\
\hline 6 & 24,0 & 665 & 14,37 \\
\hline 7 & 0,0 & 665 & 0,00 \\
\hline 8 & 0,0 & 665 & 0,00 \\
\hline 9 & 0,0 & 665 & 0,00 \\
\hline 10 & 32,0 & 665 & 19,16 \\
\hline 11 & 0,0 & 665 & 0,00 \\
\hline 12 & 5,0 & 665 & 2,99 \\
\hline 13 & 0,0 & 665 & 0,00 \\
\hline 14 & 0,0 & 665 & 0,00 \\
\hline 15 & 52,0 & 665 & 31,13 \\
\hline 16 & 62,0 & 665 & 37,12 \\
\hline 17 & 0,0 & 665 & 0,00 \\
\hline 18 & 8,0 & 665 & 4,79 \\
\hline 19 & 8,0 & 665 & 4,79 \\
\hline 20 & 37,0 & 665 & 22,15 \\
\hline 21 & 0,0 & 665 & 0,00 \\
\hline 22 & 6,0 & 665 & 3,59 \\
\hline 23 & 5,0 & 665 & 2,99 \\
\hline 24 & 5,0 & 665 & 2,99 \\
\hline 25 & 13,0 & 665 & 7,78 \\
\hline 26 & 0,0 & 665 & 0,00 \\
\hline 27 & 0,0 & 665 & 0,00 \\
\hline 28 & 0,0 & 665 & 0,00 \\
\hline 29 & 0,0 & 665 & 0,00 \\
\hline 30 & 95,0 & 665 & 56,88 \\
\hline 31 & 18,0 & 665 & 10,78 \\
\hline
\end{tabular}

Tabel 7.

Kuantitas Air Hujan Blok D-F

\begin{tabular}{cccc}
\hline \hline Hari & $\begin{array}{c}\text { Curah Hujan } \\
(\mathbf{m m})\end{array}$ & Luas Atap $\left(\mathbf{m}^{\mathbf{2}}\right)$ & $\begin{array}{c}\text { Volume supply } \\
\left(\mathbf{m}^{\mathbf{3}}\right)\end{array}$ \\
\hline 1 & 75,0 & 709 & 47,88 \\
2 & 80,0 & 709 & 51,07 \\
3 & 0,0 & 709 & 0,00 \\
4 & 0,0 & 709 & 0,00 \\
5 & 50,0 & 709 & 31,92 \\
6 & 24,0 & 709 & 15,32 \\
7 & 0,0 & 709 & 0,00 \\
8 & 0,0 & 709 & 0,00 \\
9 & 0,0 & 709 & 0,00 \\
\hline \hline
\end{tabular}

\begin{tabular}{cccc}
\hline \hline Hari & $\begin{array}{c}\text { Curah Hujan } \\
(\mathbf{m m})\end{array}$ & Luas Atap $\left(\mathbf{m}^{2}\right)$ & $\begin{array}{c}\text { Volume supply } \\
\left(\mathbf{m}^{3}\right)\end{array}$ \\
\hline 10 & 32,0 & 709 & 20,43 \\
11 & 0,0 & 709 & 0,00 \\
12 & 5,0 & 709 & 3,19 \\
13 & 0,0 & 709 & 0,00 \\
14 & 0,0 & 709 & 0,00 \\
15 & 52,0 & 709 & 33,19 \\
16 & 62,0 & 709 & 39,58 \\
17 & 0,0 & 709 & 0,00 \\
18 & 8,0 & 709 & 5,11 \\
19 & 8,0 & 709 & 5,11 \\
20 & 37,0 & 709 & 23,62 \\
21 & 0,0 & 709 & 0,00 \\
22 & 6,0 & 709 & 3,83 \\
23 & 5,0 & 709 & 3,19 \\
24 & 5,0 & 709 & 3,19 \\
25 & 13,0 & 709 & 8,30 \\
26 & 0,0 & 709 & 0,00 \\
27 & 0,0 & 709 & 0,00 \\
28 & 0,0 & 709 & 0,00 \\
29 & 0,0 & 709 & 0,00 \\
30 & 95,0 & 709 & 11,49 \\
31 & 18,0 & 709 & \\
\hline \hline
\end{tabular}

3)Penentuan Kapasitas Tangki Penampung Air Hujan (Ground Reservoir)

Pada perencanaan ini, tangki penampung air hujan direncanakan untuk penggunaan selama satu bulan. Tabel 8 menyajikan ukuran tangki penampung air hujan untuk Blok A-F.

Tabel 8.

Volume Tangki Penampung Air Hujan Blok A-F

\begin{tabular}{cc} 
Blok & Volume $\left(\mathbf{m}^{\mathbf{3}}\right)$ \\
\hline A & 24,18 \\
B & 24,62 \\
C & 25,05 \\
DA & 23,40 \\
DB & 26,00 \\
EA & 26,72 \\
EB & 25,28 \\
FA & 22,73 \\
FB & 25,28 \\
\hline \hline
\end{tabular}

4)Perancangan Sistem Talang Datar dan Talang Tegak

Perancangan sistem talang datar dan talang tegak pada perencanaan ini meliputi perhitungan diameter talang serta sistem penyaluran menuju ground reservoir. Adapun perhitungan diameter talang membutuhkan data curah hujan pada PUH 1 tahun, intensitas hujan dan luas atap perencanaan. Tabel 9 menyajikan diameter talang datar dan talang tegak untuk blok A-F. 
Tabel 9.

Diameter Talang Datar dan Talang Tegak Berdasarkan Luas Atap

\begin{tabular}{|c|c|c|c|c|c|c|}
\hline Atap & $\begin{array}{c}\mathrm{I} \\
(\mathrm{mm} / \mathrm{ja} \\
\mathrm{m})\end{array}$ & $\begin{array}{c}\text { Luas } 1 \\
\text { sisi } \\
\text { atap } \\
\text { real } \\
\left(\mathrm{m}^{2}\right) \\
\end{array}$ & $\begin{array}{c}\text { Slope } \\
\text { (dari } \\
\text { tabel) } \\
\text { (a) }\end{array}$ & $\begin{array}{c}\text { Diameter } \\
\text { Talang } \\
\text { Datar (mm) } \\
\text { (b) }\end{array}$ & $\begin{array}{c}\text { Diameter } \\
\text { Talang } \\
\text { Tegak } \\
(\mathrm{mm}) \\
\text { (c) }\end{array}$ & $\begin{array}{c}\text { Diameter } \\
\text { Pipa } \\
\text { Datar } \\
(\mathrm{mm})\end{array}$ \\
\hline \multicolumn{7}{|c|}{ BLOK A,B,C } \\
\hline Luas 1 & 89,657 & 32 & 0,01 & 100 & 50 & 80 \\
\hline Luas 2 & 139,251 & 57 & 0,01 & 125 & 50 & 80 \\
\hline Luas 3 & 83,184 & 10 & 0,01 & 80 & 50 & 80 \\
\hline Luas 4 & 89,657 & 64 & 0,01 & 125 & 65 & 80 \\
\hline Luas 5 & 78,250 & 115 & 0,01 & 150 & 65 & 100 \\
\hline Luas 6 & 72,911 & 352 & 0,01 & 200 & 100 & 150 \\
\hline Luas 7 & 84,223 & 35 & 0,01 & 100 & 50 & 80 \\
\hline \multicolumn{7}{|c|}{ BLOK D,E,F } \\
\hline Luas 1 & 83,252 & 290 & 0,01 & 200 & 100 & 125 \\
\hline Luas 2 & 66,220 & 393 & 0,01 & 200 & 100 & 150 \\
\hline Luas 3 & 83,252 & 27 & 0,01 & 100 & 50 & 80 \\
\hline
\end{tabular}

Berdasarkan Tabel 9, diameter yang digunakan cukup beragam, maka dari itu untuk mengurangi penggunaan aksesoris yang terlalu banyak maka dipakai diameter pipa yang terbesar yaitu $200 \mathrm{~mm}$. Pada perencanaan ini, talang datar akan menggunakan talang PVC setengah lingkaran sementara untuk talang tegak dan pipa datar akan menggunakan pipa PVC Tipe AW.

5) Sistem Penyaluran Air Hujan

Sistem penyaluran air hujan yang akan dibahas pada perencanaan ini adalah sistem dari talang menuju ground reservoir yang kemudian nanti di pompa ke roof tank. Roof tank pada perencanaan ini menggunakan roof tank eksisting. Sementara ground reservoir yang digunakan bergantung pada volume air hujan yang tertampung. Tabel 10 menunjukkan kapasitas ground reservoir yang dibutuhkan pada tiap gedung.

Tabel 10.

Kapasitas Ground Reservoir

\begin{tabular}{|c|c|c|l|}
\hline \multirow{2}{*}{ Blok } & \multicolumn{2}{|c|}{ Ground Reservoir } & \multicolumn{1}{|}{ Keterangan } \\
\cline { 2 - 3 } & $\begin{array}{c}\text { Eksisting } \\
(\mathbf{m} 3)\end{array}$ & $\begin{array}{c}\text { Hasil } \\
\text { Perhitungan } \\
(\mathbf{m} 3)\end{array}$ & \\
\hline A & 48 & 24,18 & Menggunakan ground cadangan \\
\hline B & 48 & 24,62 & Menggunakan ground cadangan \\
\hline C & 48 & 25,05 & Menggunakan ground cadangan \\
\hline DA & 45 & 23,40 & Menggunakan ground eksisting \\
\hline DB & 45 & 26,00 & Menggunakan ground eksisting \\
\hline EA & 45 & 26,72 & Menggunakan ground eksisting \\
\hline EB & 45 & 25,28 & Menggunakan ground eksisting \\
\hline FA & 45 & 22,73 & Menggunakan ground eksisting \\
\hline FB & 45 & 25,28 & Menggunakan ground eksisting \\
\hline
\end{tabular}

Berdasarkan Tabel 10 ground reservoir yang dibutuhkan pada Blok A-C berukuran lebih kecil daripada ground reservoir eksisting, sehingga untuk Blok A-C akan menggunakan ground reservoir eksisting.

Sementara untuk Blok D-F, ground reservoir yang dibutuhkan berukuran lebih kecil daripada ground reservoir eksisting. Sehingga untuk Blok D-F akan menggunakan ground reservoir eksisting untuk menampung air hujan.

6)Perhitungan Bill of Quantity (BOQ) dan Rancangan

Anggaran Biaya (RAB)

Perhitungan BOQ dan RAB dalam perencanaan ini meliputi:

a) Pipa dan Aksesorisnya

b) Talang dan Aksesorisnya
Tabel 11 menyajikan total rancangan anggaran biaya yang dibutuhkan.

Tabel 11.

Total Anggaran Biaya

\begin{tabular}{|r|r|r|}
\hline No & Uraian Pekerjaan & Harga (Rp) \\
\hline \multicolumn{2}{|c|}{ BLOK A-C } \\
\hline 1 & Ppn 10\% Datar, Talang dan Aksesoris & $244.758 .537,06$ \\
\hline \multicolumn{2}{|c|}{ Botal Anggaran Biaya } & $24.475 .853,71$ \\
\hline \multicolumn{2}{|c|}{ BLOK D-F } & $\mathbf{2 6 9 . 2 3 4 . 3 9 1}$ \\
\hline \multicolumn{2}{|c|}{ ppn 10\% } & $263.359 .708,71$ \\
\hline 1 & Pipa Datar, Talang dan Aksesoris & $26.335 .970,87$ \\
\hline \multicolumn{2}{|c|}{ Total Anggaran Biaya } & $\mathbf{2 8 9 . 6 9 5 . 6 8 0}$ \\
\hline \multicolumn{2}{|c|}{ TOTAL SEMUA BLOK } & $\mathbf{5 5 8 . 9 3 0 . 0 7 0}$ \\
\hline \multicolumn{2}{|c|}{}
\end{tabular}

\section{7)Penghematan Pemakaian Air Bersih}

Perhitungan penghematan pemakaian air bersih berdasarkan pada kebutuhan air PDAM perbulan dan volume air hujan yang tersedia. Tabel 12 menyajikan prosentase penghematan pemakaian air PDAM.

Tabel 12.

Prosentase Penghematan Pemakaian Air PDAM

\begin{tabular}{cc}
\hline \hline Blok & $\mathbf{P}(\%)$ \\
\hline A & $17,18 \%$ \\
B & $16,84 \%$ \\
C & $16,51 \%$ \\
DA & $19,10 \%$ \\
DB & $17,02 \%$ \\
EA & $16,50 \%$ \\
EB & $17,56 \%$ \\
FA & $19,69 \%$ \\
FB & $17,56 \%$ \\
\hline \hline
\end{tabular}

8)SOP dan Pemeliharaan Sistem PAH

Terkait dengan pemanfaatan air hujan melalui PAH, perlu memperhatikan hal-hal berikut:

a) Memastikan kebersihan air hujan yang masuk PAH.

b) Pastikan talang dan pipa terjaga kebersihannya dan jangan menampung air hujan pada 10 menit pertama.

c) Pada musim kemarau, gate vale yang ada pada pipa datar menuju reservoir air PDAM dalam keadaan tertutup.

d) Penggunaan Air PAH

e) Jika akan digunakan untuk makan/minum sebaiknya dimasak terlebih dahulu. Sementara jika digunakan untuk mencuci atau lainnya dapat langsung digunakan.

f) Memeriksa kondisi air dan membersihkan instalasi PAH secara rutin.

\section{KESIMPULAN}

Dari perencanaan sistem penampungan air hujan di Rusunawa Penjaringan Sari I dan II dapat disimpulkan beberapa hal antara lain:

a. Perencanaan sistem penampung air hujan di Rusunawa Penjaringan Sari Surabaya, menggunakan campuran antara air hujan dengan air PDAM sebagai sumber dari PAH. Dari hasil perhitungan kapasitas penampung air hujan, didapatkan bahwa untuk Blok A-C ground reservoir eksisting masih mampu menampung air hujan sehingga tidak perlu dibangun ground reservoir baru. Hal 
ini juga berlaku untuk Blok D-F yang tidak memerlukan ground reservoir baru untuk menampung air hujan.

b. Total biaya yang dibutuhkan dalam perencanaan ini adalah sebesar Rp 558.930.070 dengan rincian:

c. Total biaya untuk Blok A-C sebesar Rp 269.234.391

d. Total biaya untuk Blok D-F sebesar Rp 289.695.680

e. Prosentase penghematan terhadap biaya pemakaian air bersih PDAM selama 1 bulan sebagai berikut:

- Blok $\mathrm{A}=17,18 \%$

- Blok B $=16,84 \%$

- Blok $\mathrm{C}=16,51 \%$

- Blok DA $=19,10 \%$

- Blok DB $=17,02 \%$

- Blok EA $=16,50 \%$

- Blok EB $=17,56 \%$

- Blok FA $=19,69 \%$

- Blok FB $=17,56 \%$

\section{UCAPAN TERIMA KASIH}

Penulis mengucapkan terima kasih kepada pengelola UPT Rusunawa Penjaringan Sari I dan Penjaringan Sari II yang telah memberikan perizinan serta data untuk berlangsungnya penelitian ini.

\section{DAFTAR PUSTAKA}

[1] Sunaryo, C. D. Hidrologi teknik. Surabaya: Usaha Nasional (2005).

[2] Kim Ree-Ho, Sangho Lee, Jinwoo Jeong, Jung-Hun Lee, dan YeongKwan Kim, "Reuse greywater and rainwater using fiber filter media and metal membrane," Desalination, Vol. 202 (2007) 326-332.

[3] Pemerintah Republik Indonesia. UU RI Nomor 20 Tahun 2011 Tentang Rumah Susun (2011).

[4] Krishna, Hari J. The Texas Manual on Rainwater Harvesting. Texas (2005)

[5] Badan Standarisasi Nasional. SNI 03-7065-2005 Tentang Tata Cara Perencanaan Sistem Plambing (2005).

[6] Menteri Kesehatan Republik Indonesia. Permenkes Nomor 492/Menkes/Per/IV/2010 Tentang Persyaratan Kualitas Air Minum (2010). 